\title{
An investigation of several parameters of the horizontal-vertical illusion'
}

\author{
D. A. BEGE LMAN AMD GEORGE STEINFELD \\ F AIRFIELD HILLS HOSPITAL, NEWTOWN, CONN.
}

Length of standard line, degrees of lateral separation of $\mathrm{H}$ and $V$ stimuli, and which line served as standard or comparison stimulus were systematically varied in $a 4$ by 3 by 2 factorial design on the horizontal-vertical illusion. When illusion affects were averaged under $\mathrm{H}$ - and $\mathrm{V}$-standard conditions, a negative relationship obtained between magnitude of illusion and length of line. With vertical as standard, the illusion increased as a function of lateral separation of stimuli, but decreased with horizontal as standard. These differential trends for $\mathrm{H}$ - and $\mathrm{V}$-standard conditions contributed to the unsystematic relationship between the size of the illusion and progressive displacement of $H$ and $V$ lines. The illusion curves for three lengths of standard line across degrees of lateral separation were similar. The findings are viewed as incompatible with explanations of the H-V illusion involving the so-called "error of the standard."

The magnitude of the horizontal-vertical illusion has previously been shown to be affected by such variables as binocular vs monocular regard(Künnapas, 1957a), fixation (Künnapas, 1958), shape of an artificial visual field (Künnapas, 1957b), bisection effects (Künnapas, 1955), and the orientation of the observer or stimulus array (Finger \& Spelt, 1947; Shipley et al, 1949; Pollack \& Chapanis, 1952; Ōno, 1959; Imai, 1960; Suto, 1960; Morinaga et al, 1962). In the present experiment, an attempt was made to determine whether the illusion was also affected by spatial separation of the vertical ( $V$ ) and horizontal (H) lines, the length of the standard line, and which line, $V$ or $H$, served as the standard or comparison stimulus.

\section{Design}

\section{METHOD}

To eliminate the effects of the bisection illusion (Künnapas, 1955), a ᄀ-shaped stimulus was used. Four conditions of lateral separation of the $V$ and $H$ lines comprising $0^{\circ}, 22.5^{\circ}, 45^{\circ}$, and $90^{\circ}$ of visual arc, three lengths of standard line, 5,10 , and $20 \mathrm{~cm}$, and which line ( $\mathrm{V}$ or $\mathrm{H}$ ) served as the standard, were the parameters investigated. These variables were systematically varied in a 4 by 3 by 2 factorial design in which each of the 48 Ss served as his own control.

\section{Procedure}

Each $S$ was informed that he would be required to adjust a luminous comparison line to a standard so that they both "looked" equal in length. He was told that he would be alternately adjusting the $V$ and $H$ lines, that there would be three standard line lengths, and that the $V$ and $H$ lines would be adjacent or separated in space.

The S's head was steadied by a chin rest which assured a constant distance from eyes to stimuli of $40 \mathrm{~cm}$. The $\mathrm{S}$, however, was permitted the lateral head movement required to view successively stimuli in the $90^{\circ}$ separation condition.

Judgments were made in a totally dark room, with only the luminous lines observable, under binocular regard. The $\mathrm{S}$ made his judgment by regulating a cardboard shutter covering an aperture. He was encouraged to make each judgment as quickly as possible, without giving it too much thought.

Ss were run through counterbalanced orders of 24 separate conditions representing combinations of the three parameters under study. While each $S$ made 48 judgments, half the group or 24 Ss made them in the $\mathrm{AD}$ order, while the remaining half made them in the DA order. The average score of an $A$ and $D$ judgment was the one used in subsequent analysis. After each judgment, the $E$ recorded its magnitude by obtaining a pointer reading from a rule aligned with each comparison aperture. With the S's eyes shut, the $E$ then reset standard and comparison lines, and readied the $S$ for the next judgment.

\section{Materials}

The apparatus consisted of two $1 / 4$ in. plywood black boxes, $20 \times 20 \times 20 \mathrm{ln}$, and $20 \times 5 \times 5 \mathrm{in}$. The larger box contained two $46 \mathrm{~cm}$ slots perpendicular to each other, cut in the center of the surface of the box facing the $S$. Both slots were covered by strips of flashed opal glass, prepared so that a thin $1 \mathrm{~mm}$ luminous line appeared when the light source inside the box was turned on. Ss regulated a cardboard shutter by moving a knob up or down (vertical comparison stimulus) or sideways (horizontal comparison stimulus) in order to control the extent of luminous line exposed. The two perpendicular lines on the larger box were only used simultaneously in the $0^{\circ}$ condition. Each of these lines alternated as standard and comparison stimulus in this condition.

To obtain $22.5^{\circ}, 45^{\circ}$, and $90^{\circ}$ of separation of $V$ and $H$ lines, the second, smaller box, containing only a vertical slot, was used. This box was placed in three fixed positions to the right of the larger 
Table 1. Mean Percent llusion Scores

\begin{tabular}{rrrrrrrr} 
& & \multicolumn{2}{c}{$5 \mathrm{~cm}}$. & \multicolumn{2}{c}{$10 \mathrm{~cm}}$. & \multicolumn{2}{c}{$20 \mathrm{~cm}}$. \\
& & \multicolumn{1}{c}{$H C$} & $V C$ & $H C$ & $V C$ & $H C$ & $V C$ \\
\hline 0 & $M$ & 11.06 & 10.02 & 4.29 & 7.10 & 1.77 & 5.31 \\
& $S D$ & .09 & .10 & .06 & .07 & .06 & .07 \\
$22.5^{\circ}$ & $M$ & 11.05 & 3.06 & 5.19 & 4.31 & -.15 & 2.62 \\
& $S D$ & .11 & .08 & .10 & .08 & .08 & .07 \\
$45^{\circ}$ & $M$ & 12.42 & 2.71 & 8.00 & 5.06 & 2.60 & 3.77 \\
& $S D$ & .12 & .10 & .08 & .07 & .08 & .08 \\
$90^{\circ}$ & $M$ & 12.52 & -1.08 & 9.58 & 2.31 & 3.62 & 2.52 \\
& SD & .13 & .10 & .10 & .08 & .08 & .07 \\
\hline
\end{tabular}

box so that it represented a systematic spatial displacement of the $\mathrm{V}$ line. Naturally, the $\mathrm{V}$ line on the larger box was masked under each of the three alternative conditions of lateral displacement. Under the $0^{\circ}$ condition, the light in the smaller box was extinguished.

Partially masking the light source in the smaller box permitted $\mathrm{E}$ to equate the intensity of light emitted through slots in both boxes. The intensity of light emitted was less than $.10 \mathrm{ft}-\mathrm{c}$, as measured by a Gossen Tri-Lux Footcandle Meter.

\section{Subjects}

Subjects were 48 volunteers recruited from the staff at Fairfield Hills Hospital in Connecticut. A total of 13 men and 35 women participated, with a mean age of 26.48 years $(\mathrm{SD}=10.20)$ and a mean educational level of 13.24 years $(S D=2.36)$. All $\mathrm{Ss}$ had 20-20 vision, corrected or uncorrected.

\section{RESULTS}

The dependent variable was an illusion score obtained by applying the formula $\mathrm{X} / \mathrm{St}$, where $\mathrm{X}$ represented the amount by which a comparison judgment overestimated or underestimated the size of the standard line, and St represented the veridical length of the standard. To preserve consistency, positive signs were attached to scores for which $X$ was in the predicted direction, and negative signs to those for which $\mathrm{X}$ was in the nonpredicted direction (e.g., an illusion score of .10 would result from a vertical comparison judgment of either 5.5 or 4.5 to a $5 \mathrm{~cm}$ horizontal standard; the score in the former case, however, would be -.10 since VC judgments are most often of less, not greater, magnitude than the length of the standard). Mean percent illusion scores for each of the 24 separate conditions are given in Table 1.

An ANOVA on the data was performed, and revealed significant effects for all primary factors and first order interactions.

\section{Factor A: HC vs VC Judgments}

Horizontal comparison (HC) judgments to a verti- cal standard yielded a mean percent illusion of 6.8 . This significantly exceeded the $4.0 \%$ illusion score for vertical comparison judgments (VC) to a horizontal standard $(\mathrm{F}=8.56, \mathrm{df}=1 / 47, \mathrm{p}<.01)$. Hence, the degree of overestimation on HC judgments significantly exceeded the degree of underestimation on VC judgments, as illustrated in Fig. 1a.

\section{Factor B: Length of Line}

The ANOVA yielded a highly significant effect of line length on illusion score $(F=38.76$, $\mathrm{df}=2 / 94, \mathrm{p}$ $<.001)$. For the $5 \mathrm{~cm}$ standard line the lllusion score was $7.8 \%$; for the $10 \mathrm{~cm}$ line, $5.5 \%$; and for $20 \mathrm{~cm}, 2.7 \%$. Duncan's Multiple Range test for the separate comparisons revealed that these values differed significantly from each other at the .01 level. Thus, there is an inverse relationship between the length of the standard and the magnitude of the illusion, as illustrated in Fig. $1 \mathrm{~b}$.

\section{Factor C: Degree of Lateral Separation}

Illusion scores obtained for the $0^{\circ}, 22.5^{\circ}, 45^{\circ}$, and $90^{\circ}$ conditions of lateral separation of stimuli were $6.6 \%, 4.4 \%, 5.8 \%$, and $4.9 \%$, respectively. Although the main effect was significant $(F=2.77$, df $=3 / 141, p<.05)$, Duncan's test showed that only the $0^{\circ}$ and $22.5^{\circ}$ conditions differed. Other comparisons were nonsignificantly different from each other. Thus, the relationship between the size of the lllusion score and the progressive spatial separation of $H$ and $\mathrm{V}$ lines was unsystematic, as shown in Fig. $1 \mathrm{c}$.

\section{AB Interaction}

The data revealed a significant interaction between illusion scores for $\mathrm{HC}$ vs VC judgments as a function of line lengths ( $F=41.25, d f=2 / 94, p<.001)$. For the 5, 10 , and $20 \mathrm{~cm}$ lines, HC judgments averaged $11.9 \%, 6.8 \%$, and $2.0 \%$, respectively, whereas VC judgments averaged only $3.7 \%, 4.7 \%$, and $3.6 \%$, respectively. Figure 2a plots these trends.

Duncan's test revealed no significant changes in illusion scores for the VC judgments across the three separate line lengths, although these values all differed significantly from one another at the .01 level on HC judgments. HC judgments had significantly higher illusion scores than did VC judgments for the 5 and $10 \mathrm{~cm}$ lines, whereas the VC score of $3.6 \%$ significantly exceeded the HC score of $2.0 \%$ on the $20 \mathrm{~cm}$ line.

The trends for HC and VC judgments within the $A B$ interaction clearly indicate that the magnitude or direction of the HC-VC difference depends on the length of the standard determining comparison judgments.

Additionally, the AB interaction reveals that the inverse relation between magnitude of illusion and length of standard (Factor B) is exclusively contributed by the HC component. 

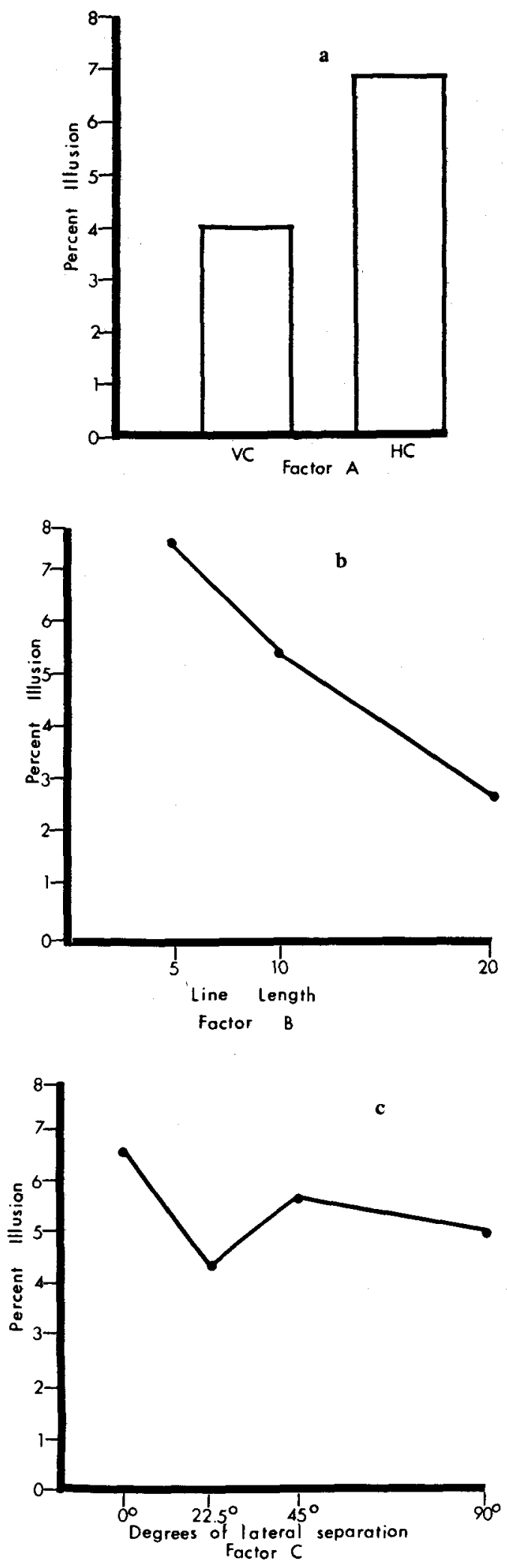

Fig. 1. Main effects.

\section{AC Interaction}

There was a significant interaction effect between degree of lateral separation and HC vs VC trends $F=7.67, \mathrm{df}=3 / 141, \mathrm{p}<.01$ ). On HC judgments, scores for $0^{\circ}-90^{\circ}$ were $5.7 \%, 5.5 \%, 7.7 \%$, and $8.6 \%$, respectively. On VC judgments they were $7.5 \%, 3.3 \%$, $3.8 \%$, and $1.3 \%$, respectively (Fig. 2b).

Only at $45^{\circ}$ and $90^{\circ}$ were $\mathrm{HC}$ and VC scores significantly different. At $0^{\circ}$ and $22.5^{\circ}$ they approximated each other. Although there was an increase in the size of the illusion from $00^{\circ}$ to $90^{\circ}$ on HC judgments, the only significant differences found by means of Duncan's test were the $0^{\circ}-90^{\circ}$ and $22.5^{\circ}-90^{\circ}$ comparisons.

The trend for VC judgments was a decrease in illusion scores from $0^{\circ}$ to $90^{\circ}$, although the only significant drop was between the $0^{\circ}$ condition and each of the three other conditions. Since the drop from $0^{\circ}$ to $22.5^{\circ}$ on HC judgments was negligible, the only significant comparison obtaining on Factor $\mathrm{C}$, that between the $0^{\circ}$ and $22.5^{\circ}$ conditions, can be viewed as an artifact of the operation of the VC judgment across these two conditions.

\section{BC Inferaction}

Figure 2c plots the interaction between line length and degree of lateral separation $(F=3.81, d f=6 / 282$, $\mathrm{p}<.01)$. For the $0^{\circ}, 22.5^{\circ}, 45^{\circ}$, and $90^{\circ}$ conditions, mean lllusion scores for the $5 \mathrm{~cm}$ line were $10.5 \%$, $7.1 \%, 7.6 \%$, and $5.7 \%$. Duncan's test revealed only that the $0^{\circ}$ condition differed significantly from the other three conditions. On the $10 \mathrm{~cm}$ line, the scores were $5.7 \%, 4.8 \%, 6.5 \%$, and $5.9 \%$, respectively. The value of $4.8 \%$ under the $22.5^{\circ}$ condition differed stgnificantly from the scores under the $45^{\circ}$ and $90^{\circ}$ conditions. All other comparisons were nonsignificant. On the $20 \mathrm{~cm}$ line, scores were $3.5 \%, 1.2 \%$, $3.2 \%$, and $3.1 \%$, respectively. Only the score for the $22.5^{\circ}$ condition differed significantly from the others.

In general, the inverse relationship between the illusion and line length was maintained at almost all degrees of lateral separation except for the differences between scores on the 5 and $10 \mathrm{~cm}$ lines at $45^{\circ}$ and $90^{\circ}$. These differences $(5 \mathrm{~cm}-7.6 \%$ vs $6.5 \%$; $10 \mathrm{~cm}-5.7 \%$ vs $5.9 \%$, respectively) were nonsignificant.

\section{DISCUSSION}

The present data would seem to suggest that how the $H-V$ lllusion is affected, either by the absolute magnitude of standard line length or degree of visual angle separation between $\mathrm{H}$ and $\mathrm{V}$ lines, depends largely on whether one is speaking about the trend for $\mathrm{HC}$ or VC judgments. The data indicate that the previously obtained finding that illusion scores for HC judgments significantly exceed those for VC 

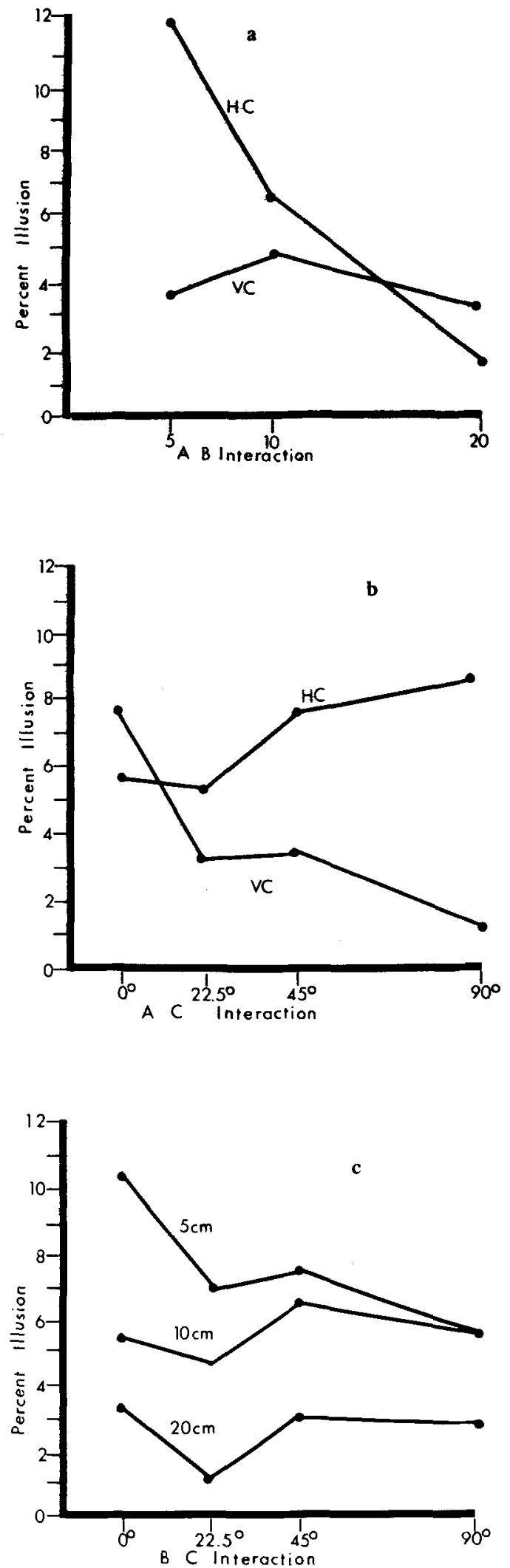

Fig. 2. Interactions. judgments do so only for specific standard line lengths and under specific conditions of spatial separation of stimuli. It would therefore appear to be premature to speak generally about the larger magnitude of HC illusion scores, without specifying the length of standard line with which such magnitudes are correlated.

This qualification would appear to cast doubt on the Gardner and Long $(1960 a, b)$ explanation of the HC-VC difference being due to an increment contributed by the so-called "error of the standard," and enhancing the magnitude of HC judgments. The present findings suggest that this concept should have only a limited generality in explaining the data, as well as raise several questions.

For one, why, on the Gardner and Long hypothesis, should the augmentation of HC Judgments reverse direction as a function of standard line length? (At $20 \mathrm{~cm}, \mathrm{VC}>\mathrm{HC}, \mathrm{p}<.05$.)

Additionally, and with respect to the $A B$ interaction, why should the dramatic drop in illusion scores across line lengths for $\mathrm{HC}$ judgments correlate with no corresponding shift in the magnitude of $\mathrm{VC}$ judgments? On the Gardner and Long hypothesis, increased scores on HC judgments should correlate with decreased scores on VC judgments. The reasoning here is that augmentation of response by the error of the standard on VC judgments competes with the tendency for these judgments to be ordinarily of smaller magnitude. These two competing processes contribute to a smaller illusion score.

Since deductions from the Gardner and Long hypothesis are often not borne out in the present data, one might assume either (1) that the error of the standard contributes unequal increments to $\mathrm{HC}$ and VC judgments, or (2) that it contributes equal increments, but that there is a basic differential illusion effect for these judgments. The first alternative flies in the face of the Gardner and Long assumption that the error of the standard contributes equal increments to both kinds of judgment. The latter alternative defeats the necessity for postulating the operation of such an error, since the construct was initially intended to explain why illusion scores for HC and VC judgments should differ.

\section{References}

Finger, F. W., \& Spelt, D. K. The illustration of the horizontalvertical illusion. J. exp. Psychol., 1947, 37, 243-250.

Garmer, R. W., \& Long, R. I. Errors of the standard and illusion effects with the inverted T. Percept. mot. Skills, 1960a, 10 , 47-54.

Gariner, R. W., \& Long. R. 1. Errors of the standard and illusion effects with L-shaped figures. Percept. mot. Skills, 1960b, 10, 107-109.

Imai, S. A review of recent studies on geometrical optical illusion. Jap. J. Psychol., 1960, 30, 366-375.

Künnapas, T. M. An analysis of the "vertical-horizontal illusion." J. exp. Psychol., 1955, 49, 134-140.

Künnapas, T. M. Interocular differences in the vertical-horizontal illusion. Acta Psychologica, 1957a, 13, 253-259. 
Kunnapas, T. M. The vertical-horizontal illusion and the visual field. J. exṕ. Psychol., 1957b, 53, 405-407.

Kưnnapas, T. M. Fixation and the vertical-horizontal illusion. Acta Psychologica, 1958, 14, 131-136.

Morinaga, S., Noguchi, K., \& Ohishi, A. The horizontal-vertical illusion and the relation of spatial and retinal orientations. Jap. psychol. Res., 1962, 4, 25-29.

Ono, S. A study on the horizontal-verticat illusion. Jinbunkenkya (Osaka City University), 1959, 10, 41-60.

Pollack, W. T., \& Chapanis, A. The apparent length of a line as a function of its inclination. Quart. J. exp. Psychol., 1952, 4, $170-178$.
Sato, Y. Study on the interdependence of the harizontal-vertical illusion and the divided illusion: 1. Jap. psychol. Res., 1960, 2, 81-93.

Shipley, W. C., Mann, B. M., \& Penfield, M. J. The apparent length of tilted lines. J. exp. Psychol., 1949, 39, 548-551.

\section{Wete}

1. Presented at the 38th annual meeting of the Eastern Psychological Association Convention, Boston, 1967.

(Accepted for publication August 1, 1967.) 